\title{
Effects of Unpolymerized Resin Components on the Function of Accessory Cells Derived from the Rat Incisor Pulp
}

\author{
M. Jontell ${ }^{1}$, C.T. Hanks ${ }^{2}$, J. Bratel ${ }^{1}$, and G. Bergenholtz ${ }^{1}$ \\ ${ }^{1}$ Department of Endodontology and Oral Diagnosis, Faculty of Odontology, University of Göteborg, Göteborg, Sweden; and 2The Department \\ of Oral Medicine, Pathology and Surgery, The University of Michigan School of Dentistry, Ann Arbor, Michigan, USA; ${ }^{*}$ to whom \\ correspondence and reprint requests should be addressed
}

\begin{abstract}
Monomeric resin components from dental composites are toxic to fibroblasts in culture and thus may interfere with the local immune system of the pulp, reducing its effective defense potential, either by cytotoxicity or by a more specific immune mechanism. Therefore, the present study was undertaken to observe the cytotoxic effects elicited by certain unpolymerized components of resin composites upon the function of accessory pulp cells in mitogen-induced proliferation of T-lymphocytes. Accessory cells from the rat incisor pulp were released following enzymatic digestion with collagenase. The assay included incubation of these cells with purified T-lymphocytes from cervical lymph nodes for $72 \mathrm{~h}$ in the presence of different concentrations of the resin components. The proliferative T-lymphocyte response was monitored by ${ }^{3} \mathrm{H}$-thymidine incorporation. Initially, we conducted experiments on spleen cells to determine the proper concentration intervals for suitable testing of the resin components. To assess the individual susceptibility of accessory cells and T-lymphocytes, we pre-treated each of these cells with some of the test materials prior to assay. At low concentrations, urethane dimethacrylate (UDMA), bisglycidyl methacrylate (bis-GMA), triethylene glycol dimethacrylate (TEGDMA), and bis-phenol A (BPA) increased spleen cell proliferation to concanavalin A (con A). Purified T-lymphocytes stimulated by pulpal cells did not show enhanced responses to UDMA, bis-GMA, glycidyl methacrylate (GMA), or N,N-dihydroxyethyl-p-toluidine (DHEpT). At higher concentrations, all substances except camphoroquinone (CAMP) showed inhibitory effects in both test systems. The in vitro study shows that resin components can evoke either immunosuppression or immunostimulation on mitogen-driven proliferation of purified T-lymphocytes and spleen cells.
\end{abstract}

Key words: dental restoration, immunocompetence, cytotoxicity, composites, lymphocytes.

Received February 18, 1994; Accepted January 19, 1995

\section{Introduction}

The elution of unpolymerized resin components becomes significant when these materials diffuse across dentin from a fresh cavity preparation and are of concentrations high enough to produce a biological effect upon the dental pulp. It is evident from previous work that certain precursor components of resins are cytotoxic for fibroblastic cells in culture (Hanks et al., 1991), and thus could contribute to tissue injury of the dental pulp following restorative procedures. The responses of the pulp to dental restorative procedures are often complex and directed by a combination of influences. Bacteria and bacterial substances are the prime suspects when restorations fail to produce a tight seal to the surrounding tooth substance (Brännström and Nyborg, 1972; Bergenholtz, 1989). Researchers often fail to ascertain other adverse biological reactions, such as effects upon immune functions. Hence, dental restorations with composites, following the release of unpolymerized components, may interfere with the function of the local immune system of the pulp, reducing its defense potential.

In previous studies, we have documented the existence of a variety of immunocompetent cells in the normal dental pulp, some of which appear to have distinct functions in pulpal immunosurveillance (Jontell et al., 1987, 1988). One of the cells which express class II molecules, a marker of immunological accessory cell function, is non-phagocytic and presents with a dendritic appearance in tissue sections (Jontell et al., 1988). Another cell shows morphological characteristics typical of macrophages. These two cell types represent the most peripheral outpost of the immune system and are essential for the proper activation of lymphocytes either locally in the pulp or in the regional lymph nodes (Jontell and Bergenholtz, 1992). It is reasonable to assume that unpolymerized resin components, following their penetration of dentin, may interfere with the function of these cells. To explore this potential, we used an in vitro system that we have developed to assess the accessory capacity of class II 
Table. 1 Components of resins, abbreviations, molecular weights, and lot numbers

\begin{tabular}{llll}
\hline Material & Abbreviation & Molec. Wt. & Use \\
\hline Bis Glycidyl Ether of Bis Phenol A & BGE-BPA & 340.45 & Lot No. \\
Bis Glycidyl Methacrylate & bis-GMA & 512.65 & Precursor \\
Bis Phenol A & BPA & 228.31 & Major oligomer \\
Camphoroquinone & CAMP & 166.24 & Precursor \\
Ethoxylated Bis Phenol A Dimethacrylate & E-BPA & 452.59 & Photo-absorber \\
Glycidyl Methacrylate & GMA & 142.17 & Precursor \\
1,6 Hexane diol Dimethacrylate & HDDM & 286.36 & Precursor \\
N,N Dihydroxyethyl-p-toluidine & DHEPT & 420.59 & Monomer \\
Tri Ethylene Glycol Dimethacrylate & TEGDMA & 286.36 & Accelerator \\
Urethane Dimethacrylate & UDMA & 498.69 & Diluent oligomer \\
\hline
\end{tabular}

molecule-expressing pulpal cells (Jontell and Bergenholtz, 1992; Jontell et al., 1994). Basically, the assay consists of incubations of suspensions of pulpal cells with purified $\mathrm{T}$ lymphocytes derived from regional lymph nodes in the presence of either mitogen or antigen.

\section{Materials and methods}

\section{Test materials}

Various resin components (Table 1) were dissolved in $100 \%$ DMSO (silylation grade; Pierce, Rockford, IL, USA), as previously described (Hanks et al., 1991). Each stock concentration was diluted $1000 \mathrm{x}$ in medium, giving a final DMSO concentration of $0.1 \%$ for each test substance. This DMSO concentration gave no statistical variation from controls with any metabolic parameter previously tested (Hanks et al., 1991). The stock solutions were used to make serial non-turbid dilutions, which were added to the cells utilized in the in vitro assay.

\section{Assay on spleen cells}

To determine concentration intervals at which the resin components would be suitable for assay, we ran experiments on concanavalin A-induced proliferation of spleen cells. An animal use protocol was reviewed and approved by an institutional review board. Spleens $(150 \mathrm{~g})$ Lewis strain (inbred) rats were removed aseptically and placed in ice-cold medium. Dulbecco's modified Eagle's medium (DMEM) containing $2 \mathrm{mmol} / \mathrm{L}$ glutamine, $10 \%$ heat-inactivated fetal calf serum (FCS), and gentamycin $(20 \mathrm{mg} / \mathrm{L})$ was used. The splenic capsule was disrupted, and the cells were released with forceps. After being washed twice in medium, the cells were placed on a FicollPaque density gradient (Pharmacia Fine Chemicals, Uppsala, Sweden) for removal of non-viable cells and erythrocytes. The splenic cells were then washed, counted, and transferred to 96well tissue culture dishes (Costar Corp., Cambridge, MA, USA) at $2.5 \times 10^{5}$ cells / well in $200 \mu \mathrm{L}$ of medium.

The stock components were diluted in DMEM with additives to obtain final concentrations. DMSO at $0.1 \%$ was used as control. The cells were incubated in medium containing concanavalin A (Con A; $5 \mu \mathrm{g} / \mathrm{mL}$, Pharmacia Fine Chemicals, Uppsala, Sweden) together with one of several resin components (Table 1) for $48 \mathrm{~h}$ in a $\mathrm{CO}_{2}$ incubator. These resin components, obtained from Esschem (Essington, PA) were urethane dimethacrylate (UDMA), bis-glycidyl methacrylate (bis-GMA), triethylene glycol dimethacrylate (TEGDMA), bis-phenol A (BPA), 1,6 hexane diol dimethacrylate (HDDM), glycidyl methacrylate (GMA), bis-glycidyl ether of bis-phenol A (BGEBPA), ethoxylated bis-phenol A dimethacrylate (E-BPA), N,Ndihydroxyethyl-p-toluidine (DHEpT), and camphoroquinone (CAMP). ${ }^{3} \mathrm{H}$-thymidine $(5 \mu \mathrm{Ci} / \mathrm{mL}$; sp. act. $25 \mathrm{Ci} / \mathrm{mmol}$; Amersham, UK) was added to each well for continued incubation over another $24 \mathrm{~h}$. The cells were harvested by a Skatron harvester (Flow Laboratories, Oslo, Norway) and washed; radioactivity was counted by liquid scintillation.

\section{Assay on pulpal cells}

Details about the methodology used in this assay and results of standard experiments have recently been published (Jontell et al., 1994) and are summarized below. Maxillary and mandibular incisors were extracted from 8- to 12-week-old Lewis rats of both sexes, wiped with gauze soaked in chlorhexidine (Hibitane Dental; ICI-Pharma, Gothenburg, Sweden), and transferred to complete DMEM on ice. The incisors were split open, and the pulps were dissected and washed in DMEM. Pieces $\left(0.1 \mathrm{~mm}^{3}\right)$ of pulp tissue were suspended in DMEM containing $0.5 \mathrm{mg} / \mathrm{mL}$ collagenase (type V, Sigma, St. Louis, MO, USA) for $30 \mathrm{~min}$ at room temperature. This incubation procedure was repeated twice at room temperature, with a change of collagenase each time. A final incubation was conducted for $30 \mathrm{~min}$ at $37^{\circ} \mathrm{C}$. The resulting cell suspensions were pooled and incubated in $0.0025 \%$ DNAase (type I, Sigma, St. Louis, MO, USA) for $3 \mathrm{~min}$ at $37^{\circ} \mathrm{C}$ to prevent cell clumping. Erythrocytes and dead cells were removed by centrifugation on a Ficoll-Paque density gradient. Prior to assay, the preparation of pulpal cells was washed twice with complete DMEM and counted.

Cervical lymph nodes were dissected from the same animals, pooled in DMEM with additives, and treated in a manner similar to that described above for spleen cells. Class II molecule-expressing cells were depleted by treatment of the suspension of lymph node cells with mouse monoclonal anti-rat class II antigen IgG (1:100; Ox6; Sera-lab Ltd, Sussex, England) overnight at $4^{\circ} \mathrm{C}$. Dynabeads M-280 (Dynal A.S., Oslo, Norway) coated with goat antimouse-IgG were added to the cell suspension, and an additional incubation was performed with gentle shaking for $60 \mathrm{~min}$ at $37^{\circ} \mathrm{C}$ and with a cell-bead ratio of 1:20. Class II molecule-expressing cells, rosetted with beads, were separated from the remaining non-rosetted cells by a 
Table 2. $\mathrm{ID}_{50} \mathrm{~s}$ for resin components in $\mu \mathrm{mol} / \mathrm{L}$

\begin{tabular}{|c|c|c|c|c|}
\hline Agents & $\begin{array}{c}\text { Splenic Lymphocytes } \\
\text { DNA Synthesis } \\
24 \mathrm{~h}\end{array}$ & $\begin{array}{c}\text { Pulp Cells + T-lymphocytes } \\
\text { DNA Synthesis } \\
24 \mathrm{~h}\end{array}$ & $\begin{array}{c}\text { Balb / c 3T3a } \\
\text { DNA Synthesis } \\
\text { 45-minute pulse }\end{array}$ & $\begin{array}{c}\text { Balb / c 3T3 }{ }^{\mathrm{a}} \\
\text { 24-hour Protein Synthesis } \\
\text { 45-minute pulse }\end{array}$ \\
\hline bis-GMA & 10.3 & 15.3 & 13 & 16 \\
\hline TEGDMA & $>50$ & NA & 66 & 100 \\
\hline CAMP & stim. only & stim. only & 235 & 270 \\
\hline DHEpT & 760 & 500 & 760 & 420 \\
\hline UDMA & 12.6 & 5.4 & 12 & 13.5 \\
\hline GMA & 6.7 & 16.7 & 48 & 58 \\
\hline BPA & 95 & NA & 28 & 28 \\
\hline BGE-BPA & $>25$ & NA & 14 & 12 \\
\hline E-BPA & 42.9 & NA & 3 & 2 \\
\hline HDDM & $>50$ & NA & 28 & 32 \\
\hline
\end{tabular}

a Data from Hanks et al. (1991).

magnet. T-lymphocytes $\left(2 \times 10^{5}\right.$ cells per well), purified in this manner, were incubated with pulpal cells $\left(10^{4}\right.$ cells per well) in the presence of Con $A$ together with each of the predetermined concentrations of 5 selected resin components (UDMA, bisGMA, GMA, DHEpT, CAMP). UDMA and bis-GMA were selected because they induced an increased proliferation of spleen cells at low concentrations. GMA and DHEpT did not display this capacity. CAMP was selected because of its unique capacity to stimulate spleen cells at all concentrations tested. All incubations were carried out at $37^{\circ} \mathrm{C}$ for $48 \mathrm{~h}$ before ${ }^{3} \mathrm{H}$ thymidine $(5 \mu \mathrm{Ci} / \mathrm{mL})$ was added for another $24 \mathrm{~h}$. The cells were harvested onto glass fiber filters in a Skatron harvester. Radioactivity reflecting the degree of proliferative response was determined on dried filters by liquid scintillation.

\section{Pre-treatment of pulpal cells and T-lymphocytes}

The individual susceptibility of accessory pulpal cells and Tlymphocytes to some of the resin components was observed in separate experiments. Prior to assay, suspensions of each of these cells were pre-treated with GMA (50 $\mu \mathrm{mol} / \mathrm{L})$, bis-GMA (25 $\mu \mathrm{mol} / \mathrm{L})$, UDMA ( $25 \mu \mathrm{mol} / \mathrm{L})$, and CAMP $(10 \mu \mathrm{mol} / \mathrm{L})$ for $4 \mathrm{~h}$ at $37^{\circ} \mathrm{C}$. The concentrations selected were within the concentration slopes predetermined in the assays described above. Following pretreatment, the cell suspensions were repeatedly washed in DMEM for removal of resin residues.

\section{Statistical methods}

We expressed our data as mean values and standard deviation of three independent experiments. Because the cpm values varied among experiments, an internal standard was included in all experiments. Hence, all data are expressed in percent of the proliferation rate in the absence of resin components. The cpm value of the internal standard never dropped below 20,000 cpm. Student's $t$ test was used to test the difference in proliferative response between incubations of cells pre-treated with the various resin composites. A difference at the $5 \%$ level was accepted as significant.

\section{Results}

When the suspension of spleen cells, which includes a variety of both accessory cells and lymphocytes, was incubated with Con $\mathrm{A}$ as a mitogen and either UDMA, bis-
GMA, TEGDMA, BPA, GMA, DHEpT, HDDM, BGE-BPA, or E-BPA (Figs. 1 to 7; Table 2), the proliferative response became depressed in a concentration-dependent fashion. The concentration of resin at which $50 \%$ of the DNA synthetic activity was depressed $\left(\mathrm{ID}_{50}\right)$ was lowest for bisGMA (10.3 $\mu \mathrm{mol} / \mathrm{L})$ and greatest for DHEpT $(760 \mu \mathrm{mol} / \mathrm{L}$; Table 2). Thus, bis-GMA was more toxic than DHEpT as measured by this parameter. When purified T-lymphocytes from cervical lymph nodes were co-incubated with pulpal cells, depression of DNA synthesis was found to be greater than when splenic cells alone were tested, for both UDMA and for concentrations of bis-GMA of $5 \mu \mathrm{mol} / \mathrm{L}$ or less (Figs. 1,3). On the other hand, DHEpT and GMA (Figs. 2, 4) did not depress the T-lymphocyte/pulp cell system to the same extent as the splenic cell system.

At low concentrations of UDMA $(0.5 \mu \mathrm{mol} / \mathrm{L}$; Fig. 1$)$, bis-

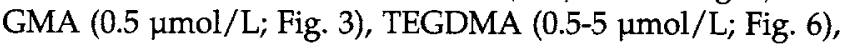
and BPA (50 $\mu \mathrm{mol} / \mathrm{L}$; Fig. 7), a stimulatory effect was noted for spleen cells. None of these four components was stimulatory to T-lymphocytes when they were co-incubated with pulpal cells. In response to CAMP, spleen cells were stimulated from 400 to $500 \%$ of the untreated controls (from 32 to $250 \mu \mathrm{mol} / \mathrm{L}$; Fig. 5). If pulpal cells were co-incubated with T-lymphocytes, the stimulatory response to CAMP was not as pronounced but was still $130 \%$ of that of the untreated controls.

When T-lymphocytes were pre-treated with GMA and activated by non-pre-treated pulpal accessory cells, there was a lower proliferative response than when non-pretreated T-lymphocytes were incubated with GMA-pretreated pulpal accessory cells (Fig. 8). These differences were statistically significant ( $p<0.05$ ). This statistically significant, varied response between the two cell populations was not seen following pre-treatment with bisGMA, UDMA, or CAMP.

\section{Discussion}

The present paper is the first to study the interaction between pulpal immune cells and resin components. These results show that, at certain concentration levels, the majority of the resin components tested in this study 

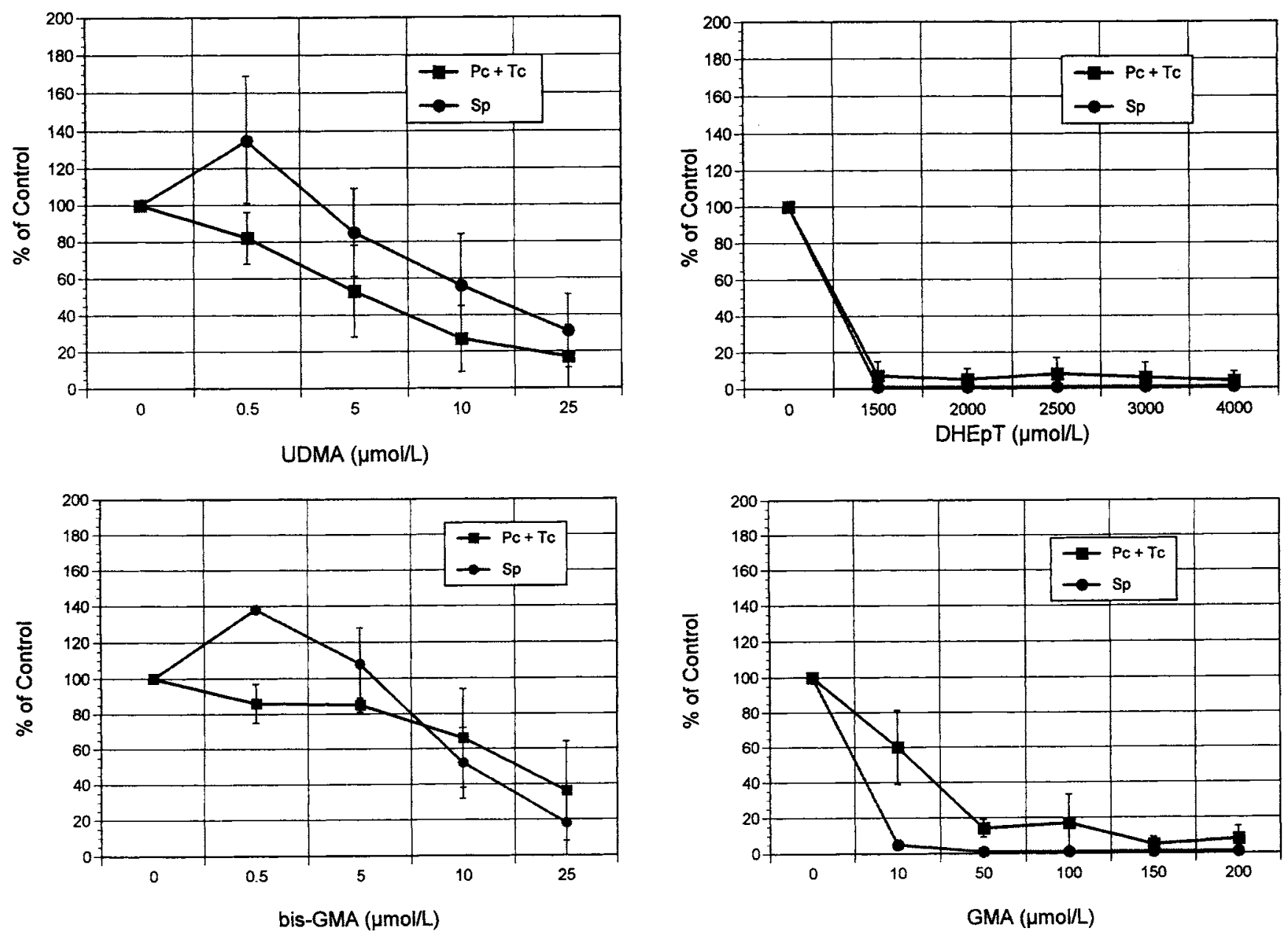

Figures 1 to 4. The effects of different concentrations of four resin components (UDMA, Fig. 1; DHEpT, Fig. 2; bis-GMA, Fig. 3; GMA, Fig. 4) in comparison with untreated controls $(0 \mu \mathrm{mol} / \mathrm{L})$ on ${ }^{3} \mathrm{H}$-thymidine incorporation into T-lymphocytes, with pulpal cells used as accessory cells $(\mathrm{Pc}+\mathrm{Tc})$, or spleen cells $(\mathrm{Sp})$ alone. The cells were incubated for $72 \mathrm{~h}$. At this time, ${ }^{3} \mathrm{H}$-thymidine was added, and the incubation continued for $24 \mathrm{~h}$. The cells were harvested, and the radioactivity was measured by liquid scintillation. Each point and error bar represent a mean value in cpm with standard deviation for three experiments, expressed as \% of untreated control.

inhibited a Con-A-driven proliferation of both spleen cells and purified T-lymphocytes. The latter cells were activated by accessory cells from the dental pulp. Therefore, analysis of these data suggests that components extractable from dental composites may not only produce deleterious effects upon stromal cells (Hanks et al., 1991), but may also impair the function of pulpal immunocompetent cells.

In general, adverse influences of dental materials on biological tissue may be attributed to either toxic or hypersensitivity reactions. With regard to toxicity, tissue damage depends, on the one hand, on the concentration gradient presented to the tissue and, on the other hand, on the cytotoxic potential of the xenobiotic chemical. Since there are no realistic estimates of the concentration levels at which unpolymerized resin components may occur in either dentinal fluid or at the contact surface with the dental pulp tissue proper following the placement of a dental restoration, it is not possible to assess if the concentrations tested in our series of experiments were clinically relevant. It is well-documented, however, that a barrier of freshly exposed dentin will not prevent the diffusion of antigenic substances to the pulp and that sufficient concentrations to induce immune pathological reactions can be built up within hours following an antigenic challenge (Bergenholtz et al., 1977). Ferracane and colleagues (Ferracane and Condon, 1990) have shown that from 85 to $100 \%$ of the extractable components from Silux are released during the first $24 \mathrm{~h}$ following polymerization, after which very little will be released. Rathbun et al. (1991) demonstrated that the toxicity was decreased by $90 \%$ following extraction of polymeric resin composites with organic solvents. These observations suggest that the highest risk for toxicity would be immediately after the placement of a composite material.

In a previous study (Hanks et al., 1991), Balb/c 3T3 fibroblasts were inhibited in a concentration-dependent fashion when these cells were exposed to the very same components as used in the current study. When the findings of that study were compared with the current data, UDMA and bis-GMA showed a strong inhibitory effect in both test systems $\left(\mathrm{ID}_{50}<20 \mu \mathrm{mol} / \mathrm{L}\right)$, suggesting a pure cytotoxic effect of these agents to both fibroblasts and 
immunocompetent cells. However, the proliferation of Balb/c 3T3 was found to be more sensitive to BGE-BPA and E-BPA than the immunocompetent cells tested in the present study. Differences of exposure time between the two cell systems cannot account for this disparate response, since the immunocompetent cells were exposed much longer to the test agents than were the $\mathrm{Balb} / \mathrm{c} 3 \mathrm{~T} 3$ fibroblasts. It is important to realize, however, that there is a principal difference between a cytotoxic effect elicited upon a passive target, such as a cell line of pure stromal cells, compared with a complex mixture of cells. Therefore, in the current assay, a variety of cells including immunocompetent cells was incubated with the test agents. In such a mixture of cells, resins may be inhibitory to some of the immunocompetent cells, while other cells may be stimulated to produce essential signals for proliferation of lymphocytes. The net result may be either decreased or increased proliferation.

The advantage of this in vitro assay is that the separated immune cells could be examined in terms of their response to various resin composites. However, it is difficult to extrapolate these data to the effects produced by these components in vivo, because the delayed hypersensitivity reaction is a complex immune reaction which is not easily monitored by in vitro assays. Variations in the response between and within different species are also common. For example, Lewis rats have been found to display an enhanced delayed hypersensitivity reaction compared with normal rats. The significance of this observation is unknown, and further studies are warranted to elucidate to what extent resin components can elicit delayed hypersensitivity reactions.

The inhibitory effects of resin components to Balb/c $3 \mathrm{~T} 3$ cells, observed by Hanks et al. (1991), correlated positively with the concentration of each component. Some of the same components-e.g., bis-GMA, UDMA, TEGDMA, and BPAstimulated mitogen-activated spleen cells when used at low concentrations. This variation appears not to be related to an inherent difference between stromal cells and

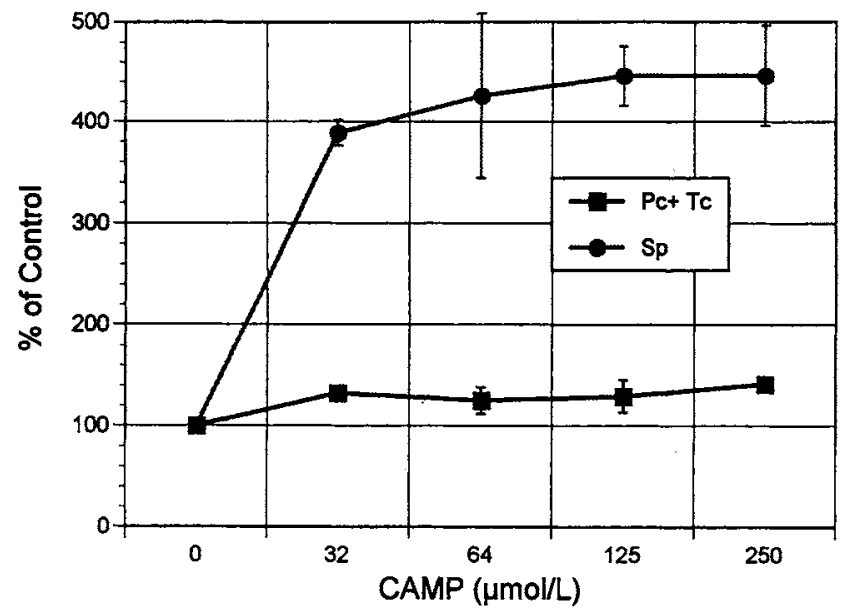

Figure 5. The effects of different concentrations of CAMP in comparison with untreated controls $(0 \mu \mathrm{mol} / \mathrm{L})$ on ${ }^{3} \mathrm{H}$-thymidine incorporation into T-lymphocytes, with pulpal cells used as accessory cells $(\mathrm{Pc}+\mathrm{Tc})$, or spleen cells $(\mathrm{Sp})$ alone. The experimental protocol and data analysis, briefly explained in Figs. 1 to 4, were followed. Each point and error bar represent a mean value in cpm with standard deviation for three experiments, expressed as \% of untreated control.

immunocompetent cells, since purified T-lymphocytes stimulated by class II molecule-expressing pulpal cells in the presence of Con A did not show this enhanced response. However, a plausible explanation for these various responses is the fact that the lymphocyte population of the spleen also contains B-lymphocytes, which may have been stimulated to proliferate. It is known from other experiments that polymers can stimulate immunocompetent cells to produce higher concentrations of cytokines than control cells (Miller and Anderson, 1988). Thus, it is possible that a modified cytokine profile contributed to an increased proliferation of B-lymphocytes at the lower concentrations
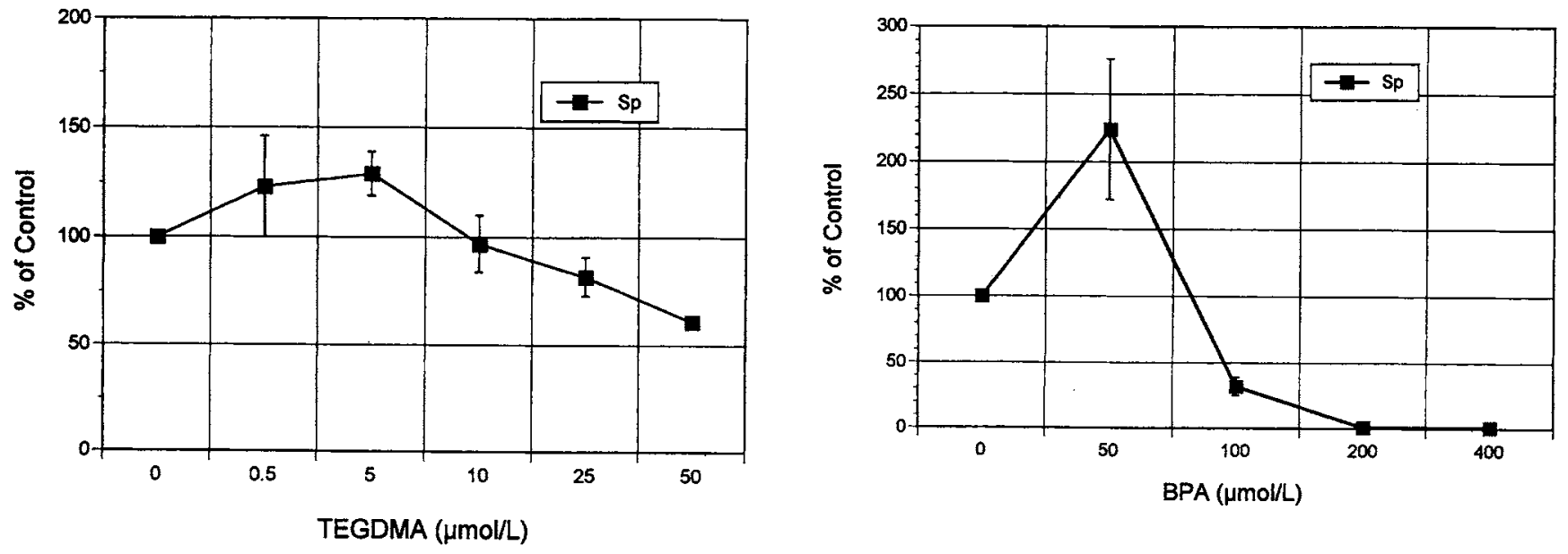

Figures 6 and 7. The effects of different concentrations of TEGDMA and BPA on proliferation of spleen cells monitored following incorporation of ${ }^{3} \mathrm{H}$-thymidine. The experimental protocol and data analysis, briefly explained in Figs. 1 to 4 , were followed. Each point and error bar represent a mean value in cpm with standard deviation for three experiments, expressed as \% of untreated control. 


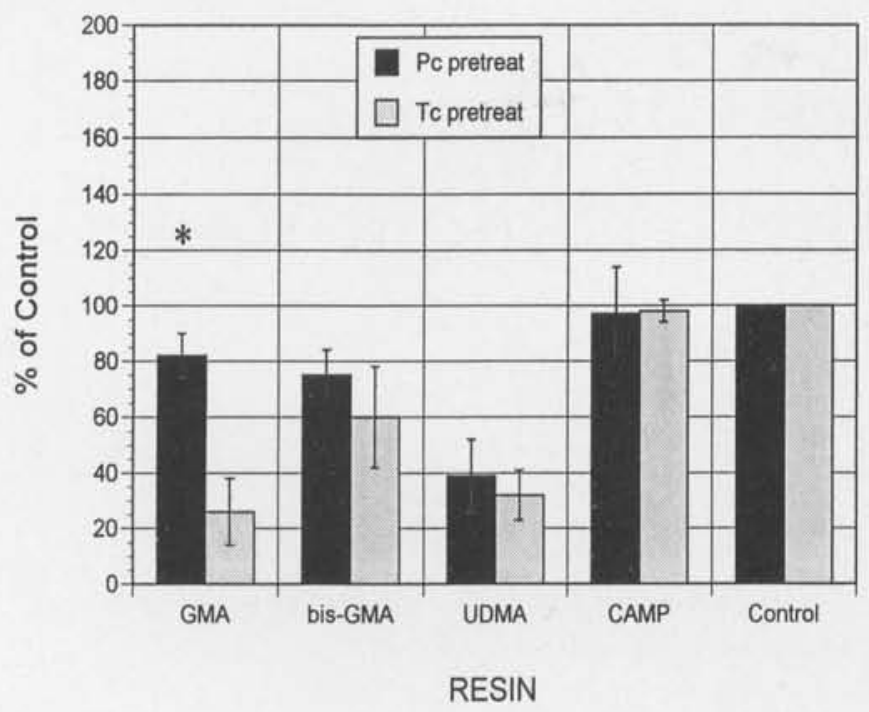

Figure 8. Either pulpal cells $(\mathrm{Pc})$ or T-cells $(\mathrm{Tc})$ were pre-treated with either GMA $(50 \mu \mathrm{mol} / \mathrm{L})$, bis-GMA $(25 \mu \mathrm{mol} / \mathrm{L})$, UDMA $(25$ $\mu \mathrm{mol} / \mathrm{L})$, or CAMP $(10 \mu \mathrm{mol} / \mathrm{L})$ for $4 \mathrm{~h}$ in $37^{\circ} \mathrm{C}$. Prior to assay, the cell suspensions were repeatedly washed for removal of resin composite residues. The experimental protocol and data analysis, briefly explained in Figs. 1 to 4 , were followed. The mean values in $\mathrm{cpm}$ and standard deviations for each point are from three experiments and are expressed as \% of the untreated control. Denotes significance at $\mathrm{p}<0.05$.

of some of the materials tested in the current study. A stimulatory effect was particularly noted for CAMP. This general effect suggests that CAMP, at some level of stimulation of lymphocytes, cooperates with Con A or is a mitogen itself. Future studies should be directed to analyze pertinent conditioned media for elaborated cytokines.

All of the components except CAMP were inhibitory at high concentrations. This effect may be explained by a general decrease in the ability to proliferate or by the killing of specific populations of cells. The latter explanation is not likely, since the separate cell types did recover after a fourhour exposure to high concentrations of the resin components. A killing effect would probably have totally abrogated proliferation and would not have appeared as the concentration-dependent inhibition observed.

Several studies lend support to the concept that bacterial leakage around composite restorations, rather than cytotoxicity, is responsible for most emerging inflammatory pulp lesions (Brännström and Nyborg, 1972; Bergenholtz et al., 1982; Cox et al., 1987). It is tempting to speculate that inflammation and necrosis of the pulp on many occasions may be the result of a combined effect of material-related cytotoxicity and bacterial infection. There is compelling evidence that many chemicals adversely affect the immune system and that chemically induced immunosuppression is often correlated with decreased host resistance to infectious agents (Luster, 1989). Consequently, immunosuppression of pulpal immunocompetent cells elicited by resin components may enhance the potential for bacterial injury to the pulp tissue. Thus, increased incidence and severity of pulpal infection are justifiable concerns following exposure of the tissue to immunotoxic chemicals.

\section{Acknowledgments}

We thank Christina Eklund and Elena Linder for their technical assistance.

This study was supported by: the Faculty of Odontology, University of Göteborg; the National Institute of Dental Research (USPHS; Grant P50 DE 09296); and the Swedish Medical Research Council (Grant 08698).

\section{References}

Bergenholtz G (1989). Bacterial leakage around dental restorations-impact on the pulp. Proceedings of symposium. In: Quality evaluation of dental restorations. Anusavice KJ, editor. Chicago: Quintessence Publishing Co., pp. 243-254.

Bergenholtz G, Ahlstedt S, Lindhe J (1977). Experimental pulpitis in immunized monkeys. Scand J Dent Res 85:390406.

Bergenholtz G, Cox CF, Loesche WJ, Syed SA (1982). Bacterial leakage around dental restorations: its effect on the dental pulp. J Oral Pathol 11:439-450.

Brännström M, Nyborg H (1972). Pulpal reaction to composite resin restorations. J Prosthet Dent 27:181-189.

Cox CF, Keall CL, Keall HJ, Ostro E, Bergenholtz G (1987). Biocompatibility of surface-sealed dental materials against exposed pulps. J Prosthet Dent 57:1-8.

Ferracane JL, Condon JR (1990). Rate of elution of leachable components from composite. Dent Mater 6:282-287.

Hanks CT, Strawn SE, Wataha JC, Craig RG (1991). Cytotoxic effects of resin components on cultured mammalian fibroblasts. J Dent Res 70:1450-1455.

Jontell M, Bergenholtz G (1992). Accessory cells in the immune defense of the dental pulp. Proc Finn Dent Soc 88(Suppl 1):344-355.

Jontell M, Bergenholtz G, Scheynius A, Ambrose W (1988). Dendritic cells and macrophages expressing class II antigens in the normal rat incisor pulp. J Dent Res 67:1263-1266.

Jontell M, Eklöf C, Dahlgren U, Bergenholtz G (1994). Difference in capacity between macrophages and dendritic cells from rat incisor pulp to provide signals to concanavalin A stimulated T lymphocytes. J Dent Res 73:1056-1060.

Jontell M, Gunraj MN, Bergenholtz G (1987). Immunocompetent cells in the normal dental pulp. J Dent Res 66:1149-1153.

Luster MI (1989). Immunotoxicology and the immune system. Health Environ Dig 3:1-3.

Miller K, Anderson JM (1988). Human monocyte/macrophage activation and interleukin 1 generation by biomedical polymers. J Biomed Mater Res 22:713-731.

Rathbun MA, Craig RG, Hanks CT, Filisko FE (1991). Cytotoxicity of a BIS-GMA dental composite before and after leaching in organic solvents. J Biomed Mater Res 25:443-457. 